\title{
Analisis numerik karakteristik intensitas suara gending Jawa
}

\author{
N. Finahari*, G. Soebiyakto \\ Teknik Mesin, Fakultas Teknik, Universitas Widyagama Malang, Jl. Taman Borobudur Indah 3 Malang \\ Jawa Timur 65128, Indonesia, Telp. (0341) 492282 ext. 328 \\ *Email: nfinahari@widyagama.ac.id
}

\section{ARTICLE INFO}

Article History:

Received 13 January 2017

Accepted 30 January 2017

Available online 30 June 2017

Keywords:

Sound signal

Javanese gending

Numerical modeling

Propagation of vibration

Excitation force

\section{ABSTRACT}

The use of Javanese Gending as music therapy is conducted by the method of stereo playback. With reference to that flow into the voice information left and right ears are different but ended in the same area, it is necessary to an understanding of the response mechanisms that emerged from each of the groove and the existence of interactions. Overview of acoustic parameter response interaction right brain hemisphere and the left brain are manifested in the form of a mathematical equation. This study aims to formulate sound characteristic of Javanese music in numerical form, as a sound source of the study. In this case, the numerical model obtained will be used as the excitation force vibration system that enters the auditory system.

\section{PENDAHULUAN}

Respon terhadap suara musik tergantung pada jenisnya.Musik klasik adalah jenis musik yang umum dikaitkan dengan kondisi fisiologis dan psikologis manusia sehingga banyak digunakan untuk keperluan terapi (Rauscher et al., 1995). Namun demikian, bagi masyarakat Jawa, Langgam Jawa terbukti lebih efektif $(p<0,05)$ menurunkan rasa nyeri dan kecemasan pada ibu yang akan melahirkan (Safitri et al., 2012) jika dibandingkan dengan Mozart. Hal ini menunjukkan bahwa latar belakang suku dan budaya subyek penelitian diduga ikut berpengaruh, khususnya jika dikaitkan dengan aspek psikologis.

Bentuk respon terhadap musik bisa ditelusuri dari aspek psikoakustik musik. Psikoakustik adalah ilmu yang mempelajari respon psikologis dari persepsi terhadap karakteristik fisik suara dasar (lakovides et al., 2004). Karakteristik psikoakustik musik tidak terbatas pada pitch, intensitas, dan timbre, tetapi juga melibatkan ritme. Ritme merupakan variabel waktu (Krumhansl, 2000). Dalam hal ini, variabel waktu dan frekuensi memegang peranan yang sama penting dalam pembentukan persepsi terhadap sinyal suara pada korteks auditori primer (Griffiths, 1999). Neuron pada area inti korteks auditori merespon stimulus nada murni, sementara area periferal lebih aktif merespon suara-suara kompleks (Hudspeth and Konishi, 2000). Kajian terhadap proses pemersepsian musik dan mekanisme pengaruhnya terhadap manusia dapat dilakukan dengan cara (lakovides et al., 2004) mengenali jenis-jenis musik, mempelajari pengalaman emosional yang muncul saat bermusik, mempelajari perubahan psikologis dan psikosomatis saat bermusik, dan mempelajari karakteristik psikoakustik dari musik.

Neuron sensor derajat satu pada cabang koklear di setiap syaraf vestibulokoklear (VIII) pada telinga, bermuara pada nuklei koklear medula oblongata di sisi yang sama (Tortora, 2005). Hal ini berarti sinyal dari telinga kiri akan diterima medula oblongata kiri dan begitu pula dengan yang kanan. Pada nuklei koklear, akson pembawa sinyal auditori diproyeksikan ke nuklei olivari superior pada pons di kedua sisi. Perbedaan waktu 
datangnya sinyal dari kedua belah telinga memungkinkan manusia untuk menentukan sumber suara. Dari nuklei olivari superior di kedua sisi, akson naik menuju kolikulus inferior pada otak tengah untuk selanjutnya diteruskan ke badan genikulasi medial di talamus. Dari talamus, sinyal auditori diproyeksikan ke area auditori primer pada girus temporal superior korteks selebral (Area Brodmann). Karena banyak akson auditori pada medulla yang bersilangan sementara sebagian lainnya tetap berada pada sisi asalnya, maka area auditori primer bisa menerima sinyal dari kedua belah telinga. Alur sinyal suara ini penting diketahui dalam kaitannya dengan pemanfaatan suara sebagai media terapi. Penelitian ini bertujuan untuk merumuskan karakteristik suara gending Jawa dalam bentuk numerik, sebagai sumber suara kajian. Dalam hal ini, model numerik yang didapatkan akan difungsikan sebagai gaya eksitasi sistem getaran yang memasuki sistem pendengaran.

\section{Alur Induksi Musik Pada Otak Manusia}

Beberapa hasil penelitian menunjukkan bahwa pendidikan musik formal berpengaruh terhadap anatomi (Gaser and Schlaug, 2003; Schneider et al., 2005) dan fisiologi otak (Gaab and Schlaug, 2003). Volume materi abu-abu otak pemusik tampak lebih besar dibandingkan dengan non pemusik pada area perirolandik, yang meliputi area motor primer, somatosensori, premotor, anterior superior parietal dan inferior temporal girus, di kedua sisi.Korelasi positif antara peningkatan volume materi abu-abu dengan status pemusik juga ditemukan pada serebelum kiri, girus Heschl kiri dan girus frontal inferior kiri. Area-area tersebut merupakan area kritis yang berperan pada persiapan, perencanaan, eksekusi dan pengaturan sekuensial bimanual pergerakan jarijari tangan. Beberapa penelitian menunjukkan bahwa perubahan volume materi abu-abu tersebut disebabkan plastisitas neural yang merespon tuntutan lingkungan (Gaab and Schlaug, 2003), selain akibat faktor alami yang terbawa sejak lahir. Pengaruh lingkungan terhadap plastisitas otak tampak dari penelitian pada tikus, dimana tikus yang diberikan paksaan untuk berlatih akrobatik secara rutin menunjukkan perubahan mikro struktur pada serebelum, korteks motor primer dan hipokampus (Anderson et al., 1994).

Perbedaan struktural yang ditemukan pada girus Heschl kiri berhubungan dengan perbedaan sumber aktivitas neurofisiologis otak saat mendengarkan musik (Gaser and Schlaug, 2003). Diketahui bahwa pelatihan tersebut meningkatkan jumlah sinaps per neuron, jumlah sel glial dan volume glial per sel purkinje pada korteks serebelar (Anderson et al., 1994). Diketahui juga bahwa terjadi peningkatan aktivitas neural pada area lobe temporal superior posterior di kedua sisi otak pada saat dilakukan pelatihan pengucapan kata-kata asing yang mengandung unsur bunyi musikal (Wong et al., 2007). Area tersebut berkaitan dengan pengklasifikasian pola suara. Pada saat pelatihan berakhir dengan keberhasilan, tampak bahwa area girus temporal superior posterior meningkat aktivitas neuralnya. Subjeksubjek yang mengalami kegagalan dalam pelatihan tersebut menunjukkan aktivitas neural yang dominan di area frontal, yaitu area yang berkaitan dengan perhatian dan pembuatan keputusan. Area ini juga aktif secara dominan saat proses pelatihan berlangsung bagi subjek yang nantinya akan gagal.

Meskipun girus Heschl dan korteks auditori primer merupakan area utama yang terlibat dalam aktivitas pemrosesan data musikal (Wong et al., 2009), diketahui bahwa ada area-area lain yang memberikan masukan pada kedua area tersebut. Area-area level bawah itu meliputi beberapa area subkortikal pada talamus dan batang otak. Dalam hal ini, batang otak merupakan area pertama yang merespon sinyal auditori dalam bentuk respon frekuensi ikutan (frequency-following response/ FFR). FFR adalah potensial elektrik yang muncul dari aktivitas sinkron neuron pada batang otak rostral. Sinyal respon ini mendeteksi frekuensi dasar input dalam bentuk pitch. Pemusik menunjukkan tingkat aktivitas FFR yang lebih tinggi dibandingkan dengan non pemusik.

Paparan musik juga dikaitkan dengan perubahan emosi pendengarnya. Musik merupakan stimulus universal yang sangat berpotensi menginduksi suasana hati. Dari sisi pandang IImu Syaraf Kognitif (cognitive neuroscience), emosi memiliki komponenkomponen. Dalam hal ini terdapat perbedaan mendasar antara mengalami emosi secara sadar (merasakan), mengekspresikannya (merespon: somatik, fisiologis dan reaksi perilaku) dan mengenalinya sebagai pengetahuan (Tsuchiya and Adolphs, 2007). Respon emosional bisa terjadi tanpa harus didahului proses mengalami emosi secara sadar. Artinya, respon bisa muncul tanpa perlu didahului adanya rasa (Craig, 2002). Mendengarkan musik merupakan salah satu kejadian dimana respon emosional bisa muncul tanpa perlu didahului adanya perasaan emosi.

Area-area otak yang terlibat dalam pembentukan komponen-komponen respon emosional adalah hipotalamus dan nuklei batang otak terlibat dalam kontrol otonom eferen, amigdala dan korteks prefrontal ventromedial terlibat dalam kontrol otonom tingkat tinggi, sementara insula dan korteks yang terkait dengan somatosensor kanan berperan pada pengalaman 
sadar emosional (Tsuchiya dan Adolphs, 2007). Korteks prefrontal ventromedial merupakan area terpopuler yang diteliti untuk tema emosi. Area ini diduga berperan penting dalam proses pemicuan berbagai respon emosional terhadap rangsangan yang bersifat multi stimulus. Dugaan tersebut telah dibuktikan melalui studi aktivasi functional magnetic resonance imaging/fMRI (Critchley et al., 2000). Penelitian tersebut juga menunjukkan bahwa area korteks prefrontal ventromedial juga terlibat pada pengaturan aspek-aspek fisiologis dari respon emosional seperti mengubah laju detak jantung, rasa kedinginan dan perubahan tekanan darah. Namun demikian, substrat neural dari respon emosional (perasaan) belum bisa dideteksi.

Jika area korteks prefrontal ventromedial merupakan area yang terlibat dalam pembentukan respon emosional, maka insula dan korteks somatosensori kanan adalah area yang aktif dalam pengalaman merasakan emosi (Adolphs, 2002). Dapat dikatakan bahwa area korteks prefrontal ventromedial bertanggung jawab atas aspek objektif emosi sementara korteks somatosensori kanan terlibat dalam aspek subjektifnya. Dengan demikian input stimulus emosi berpengaruh pada area korteks somatosensori kanan lebih dulu sebelum menstimulasi area korteks prefrontal ventromedial. Korteks somatosensori kanan juga mempengaruhi perubahan kondisi fisiologis tubuh terkait dengan munculnya emosi, termasuk perubahan-perubahan yang diinduksi korteks prefrontal ventromedial. Selengkapnya, struktur jaringan yang terlibat dalam rangkaian aksi reaksi terhadap stimulus penginduksi emosi adalah korteks somatosensori primer dan sekunder yang dihubungkan pada insula dan amigdala oleh jaringan somatosensori limbik (Friedman et al., 1986), sedangkan korteks prefrontal ventromedial, korteks singulat anterior (Öngür and Price, 2000) dan struktur subkortikal (Öngür et al., 1998), dihubungkan oleh jaringan prefrontal medial.

\section{Respon Otak Dan Sistem Syaraf Terhadap Karakteristik Musikal}

Telah diketahui sebelumnya bahwa pada tingkat sinaptik, sinyal musik menyebabkan peningkatan jumlah sinaps per neuron, jumlah sel glial dan volume glial per sel purkinje pada korteks serebelar (Anderson et al., 1994). Peningkatan aktivitas neural ini khususnya merespon karakteristik frekuensi dan pitch suara (Wong et al., 2009). Kemampuan korteks auditori dalam merespon frekuensi bisa dikuatkan jika subjek memfokuskan perhatian pada sinyal suara pemicu selama proses mendengarkan (Okamoto et al., 2009). Temuan ini sangat membantu proses penyelesaian tugas berbasis perintah auditori pada lingkungan yang bising. Sebelumnya, Okamoto et al. (2007) membuktikan bahwa dalam lingkungan bising, belahan kiri hemisfer otak lebih responsif.

Syaraf-syaraf auditori memberikan respon yang berbeda terhadap intensitas suara sinyal input. Aktivitas neural pada rentang input intensitas rendah berubah secara proporsional mengikuti perubahan input (Lütkenhöner, 2007). Perubahan tersebut mengikuti fungsi linier pada rentang input intensitas tinggi. Pada rentang intensitas medium, aktivitas respon neural justru dipengaruhi tekanan suara input (nilai logaritmik intensitas suara), dan membentuk hubungan linieritas.

\section{Respon Otak Dan Sistem Syaraf Terhadap Karakteristik Musikal}

Telah diketahui sebelumnya bahwa pada tingkat sinaptik, sinyal musik menyebabkan peningkatan jumlah sinaps per neuron, jumlah sel glial dan volume glial per sel purkinje pada korteks serebelar (Anderson et al., 1994). Peningkatan aktivitas neural ini khususnya merespon karakteristik frekuensi dan pitch suara (Wong et al., 2009). Kemampuan korteks auditori dalam merespon frekuensi bisa dikuatkan jika subyek memfokuskan perhatian pada sinyal suara pemicu selama proses mendengarkan (Okamoto et al., 2009). Temuan ini sangat membantu proses penyelesaian tugas berbasis perintah auditori pada lingkungan yang bising. Sebelumnya, Okamoto et al. (2007) membuktikan bahwa dalam lingkungan bising, belahan kiri hemisfer otak lebih responsif.

Syaraf-syaraf auditori memberikan respon yang berbeda terhadap intensitas suara sinyal input. Aktivitas neural pada rentang input intensitas rendah berubah secara proporsional mengikuti perubahan input (Lütkenhöner, 2007). Perubahan tersebut mengikuti fungsi linier pada rentang input intensitas tinggi. Pada rentang intensitas medium, aktivitas respon neural justru dipengaruhi tekanan suara input (nilai logaritmik intensitas suara), dan membentuk hubungan linieritas.

Perbedaan nilai pitch suara input akan membangkitkan respon pada area korteks auditori (terutama belahan kanan) yang berbeda, demikian juga dengan jenis sel yang meresponnya (Arlinger et al., 1982). Ditengarai bahwa nilai-nilai pitch tersebut akan ditransmisikan ke area-area khusus pada korteks auditori, untuk direspon sel-sel yang berbeda. Jadi, area respon dan jenis sel yang merespon bersifat spesifik terhadap nilai pitch tertentu.Namun demikian, pergeseran area dan jenis sel bisa terjadi, karena spesifisitas respon tersebut tidak stabil.Perubahan respon tersebut bisa terjadi dalam skala hari atau bulan (Janata et al., 2002). Selain pitch, area korteks auditori kanan juga terlibat pada respon irama, melodi dan harmoni. Selain itu, ditengarai ada area yang 
sensitif terhadap perubahan nada. Area-area tersebut meliputi korteks prefrontal medial, serebelum, sulki temporal superior pada kedua belahan otak, dan girus temporal superior.

Respon terhadap variasi irama tergantung pada perbandingan intervalnya (Tramo, 2001). Irama dengan perbandingan interval biasa (1:2 atau 1:3) akan direspon oleh korteks frontal dan parietal kiri, serta serebelum kanan. Jika melibatkan perbandingan rumit, misalnya $1: 1,25$, maka korteks serebral dan serebelum akan ikut teraktivasi. Munculnya persepsi terhadap irama diduga berhubungan dengan tingkat aktivitas elektris otak. Aktivitas otak pada interval gamma (20-60 Hz) muncul pada pencatatan EEG ketika terinduksi irama sederhana. Aktivitas gamma tersebut hanya merespon fase bunyi pada irama, tapi tidak merespon fase jeda (diam). Jika dikaitkan dengan melodi, korteks singulat posterior (area emosi), yang akan teraktivasi. Dalam hal ini nada dipandang memberikan karakter pada tekanan pengucapan kata-kata, jadi mengandung muatan emosional. Karakter-karakter musikal mampu memberikan efek dramatis pada ucapan.

Bentuk spektral (envelope) adalah salah satu karakter yang menjadi ciri warna suara

(timbre). Ciri yang lain meliputi pitch, durasi, dan intensitas suara. Pada saat otak memproses sinyal suara dalam bentuk amplop spektral, terjadi koneksi linier antara girus Heschl's dengan planum temporal (Kumar et al., 2007). Hubungan itu berlanjut dengan koneksi antara planum temporal dengan sulkus temporal superior. Ketiga area tersebut membentuk arsitektur analisis spektral dalam kerangka komputasi. Dalam hal ini planum temporal bertindak sebagai terminal komputasinya. Area planum temporal diduga memiliki pola dasar identifikasi obyek suara yang terkait dengan bentuk spektral tertentu.

\section{METODOLOGI}

\section{Hipotesis Penelitian}

Skema pohon penelitian yang memperlihatkan posisi kajian dalam artikel, ditunjukkan pada gambar 1. Ruang lingkup kajian disajikan pada gambar 2. Kajian dalam artikel ini merupakan bagian dari proses pemodelan matematis dari suara gending Jawa yang memasuki rongga telinga. Numerisasi suara gending ini akan digunakan sebagai gaya eksitasi bagi system getaran pada gendang telinga untuk proses penentuan spesifisitas psikoakustik dan farmakologi gending.

Dengan mengacu bahwa suara gending dapat diambil sampel data intensitasnya dalam bentuk numerik pada rentang waktu stereo playback, maka data sampel tersebut dapat ditampilkan dalam bentuk grafik dan diduga akan menghasilkan karakteristik yang unik sesuai jenis gendingnya.

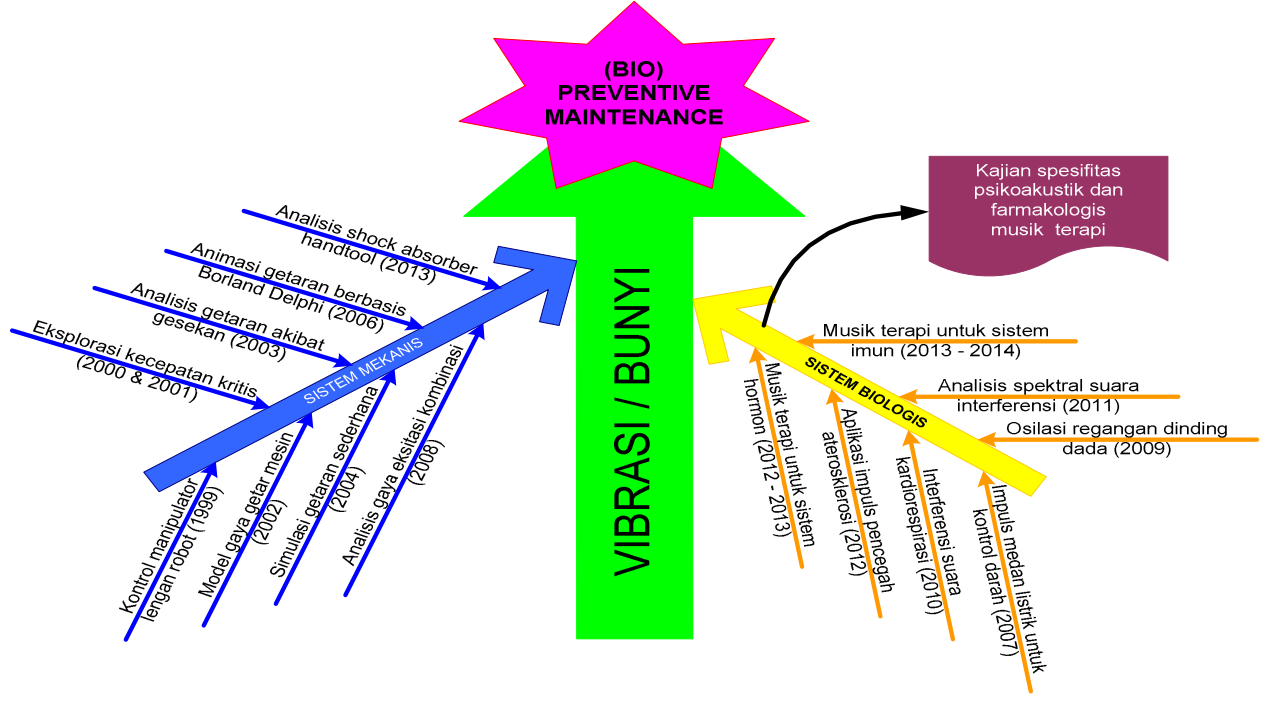

Gambar 1. Pohon penelitian yang menunjukkan posisi kajian artikel 


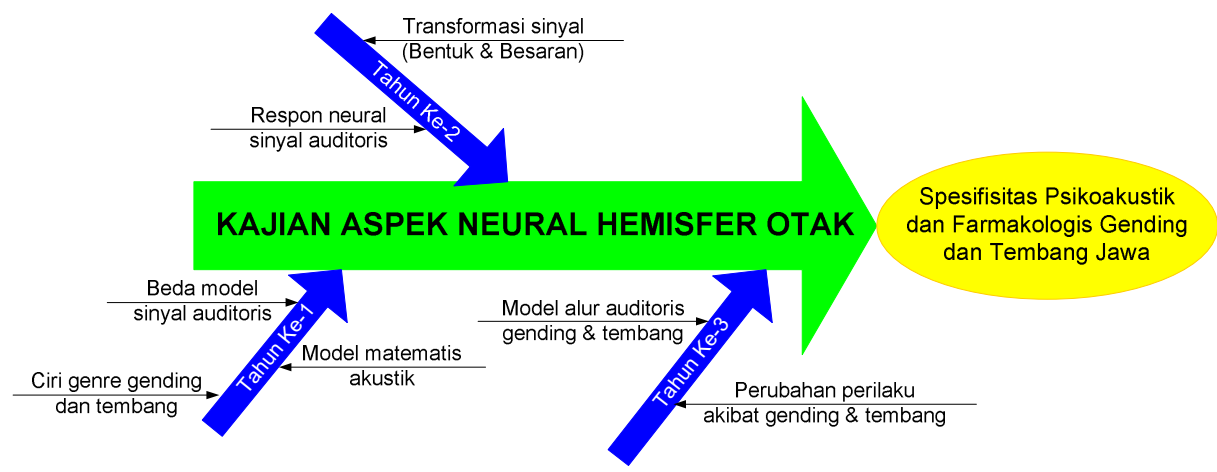

Gambar 2. Ruang lingkup kajian spesifitas psikoakustik dan farmakologi gending Jawa

\section{Prosedur Pengambilan Data}

Kajian numerik terhadap karakteristik intensitas bunyi dari setiap jenis gending Jawa dilakukan dengan mengambil data numerik intensitas suara gending saat dilakukan playback pada Program Analisis Suara berbasis Audacity. Data yang dipergunakan adalah hasil sampling temporal. Data ini akan diolah menggunakan
Program Microsoft Excell v.2010 untuk mendapatkan persamaan regresinya. Acuan yang digunakan untuk menetapkan model regresi yang sesuai adalah nilai kuadrat variabel R. Model regresi yang diperoleh akan dianalisis secara statistik untuk menguji kesamaan bentuk umumnya dengan menggunakan program SPSS ver. 17.0.

Tabel 1. Daftar gending Jawa yang dikaji

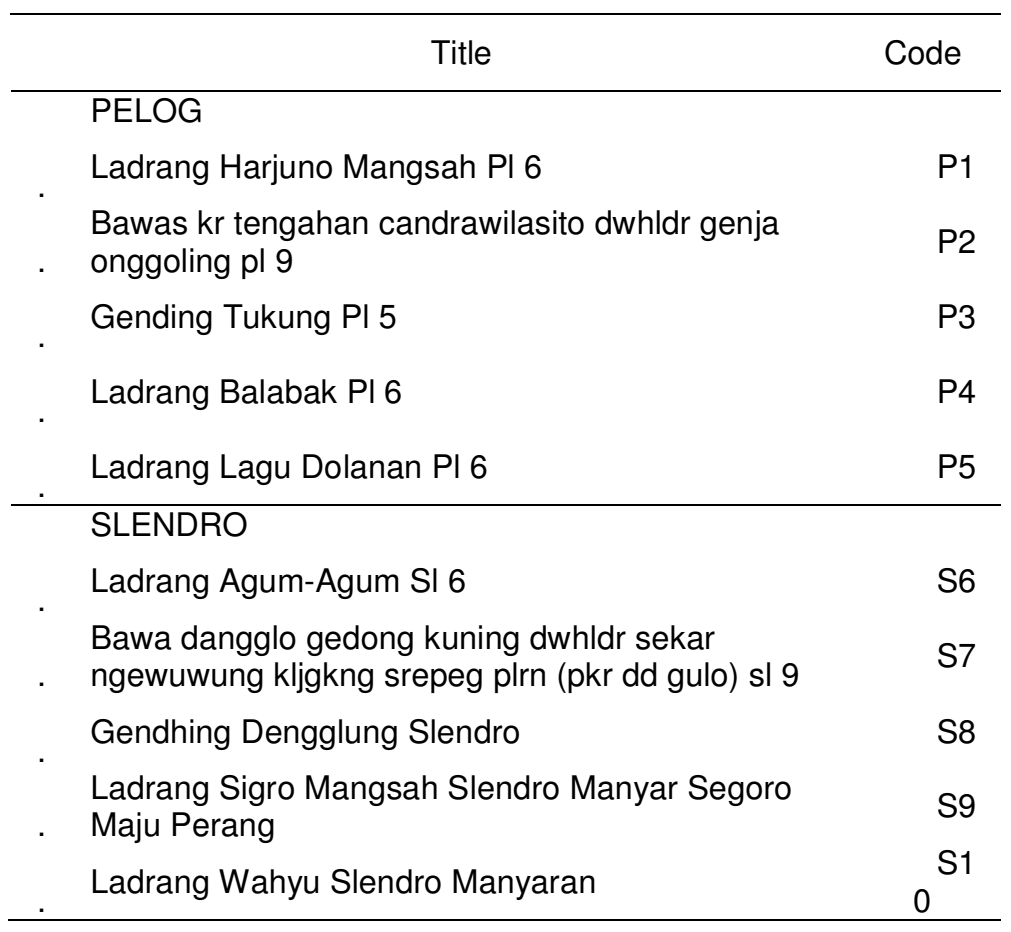

\section{HASIL DAN PEMBAHASAN}

Data gending yang menjadi kajian ditampilkan pada Tabel 1. Visualisasi data sampling intensitas suara per gending untuk 100 data per waktu stereo playback tiap gending, ditampilkan pada gambar 3 .

Hasil kajian terhadap pola akustik gending Jawa (gambar 3) menunjukkan bahwa suara 
gending dan tembang Jawa memiliki pola grafis amplitudo yang berbeda antara suara kanan dan kiri. Secara umum, pola-pola tersebut mendekati model matematis parabolik yang berulang, maka persamaan umumnya didekati dengan persamaan polinomial. Perulangan pola tersebut diduga menunjukkan parameter frekuensi sehingga tampak bahwa gending dan tembang Jawa, ratarata bertempo rendah (hanya terdapat $2-3$ ulangan pola dalam keseluruhan lagu). Dengan mengacu bahwa pola amplitudo yang diambil untuk setiap lagu adalah 100 sampling, maka ratarata frekuensi gending dan tembang Jawa adalah 0.3 - 0.5 per durasi lagu. Untuk melihat apakah hasil pemodelan tahun pertama ini merupakan temuan yang spesifik, dilakukan beberapa perbandingan dengan jenis-jenis lagu yang lain (gambar 4). Tampak bahwa gending dan tembang pembanding juga memiliki perbedaan pola suara kanan dan kiri, sementara untuk lagu populer dan dangdut pola amplitudo kanan dan kirinya sama. Untuk frekuensi, tampaknya tidak ada perbedaan pada semua jenis lagu tersebut.

Untuk menguji bahwa perulangan pola tersebut adalah wujud dari parameter frekuensi, maka nilai statistik perulangan pola tersebut semestinya tidak menunjukkan adanya perbedaan. Mayoritas hasil uji statistik (tabel 2) menunjukkan bahwa perulangan pola amplitudo tersebut memiliki nilai yang sama, sehingga banyaknya perulangan memang mengindikasikan wujud frekuensi.

Model matematis gending dan tembang Jawa yang menjadi kajian penelitian tahun pertama dapat dilihat pada gambar 5 dan rangkumannya ditunjukkan pada tabel 3 dalam penelitian ini.

Gambar 6 menunjukkan pemodelan untuk gending pembanding dan tabel rangkuman orde persamaan polinomialnya. Dari hasil analisis orde tersebut tampak bahwa modus orde untuk persamaan polinomial yang diterapkan sebagai model pendekatan pola grafis amplitudo gending dan tembang Jawa adalah 4. Maka secara umum dapat diverifikasikan bahwa persamaan matematis untuk aliran amplitudo gending dan tembang adalah sebagai berikut.

$$
f(x, t)=a x^{4}+b x^{3}+c x^{2}+d x+e
$$

dengan $f(x, t)$ adalah fungsi perubahan amplitudo suara yang juga sama dengan $P / P_{o}, p$ merupakan tekanan suara sesaat (Pascal); $P_{o}$ adalah tekanan suara acuan, bernilai $20 \mu \mathrm{Pa}$ pada frekuensi ambang pendengaran $1 \mathrm{kHz} ; x$ adalah amplitudo dalam satuan $\mathrm{dB}$ (decibel); $t$ merupakan waktu (detik); a, b, c, d, e adalah konstanta sembarang. Rambatan suara dalam medium udara dinyatakan melalui persamaan:

$v=\frac{\rho}{A Z}$

dengan $v$ adalah kecepatan rambatan suara dalam medium, $A$ adalah luas area $\left(\mathrm{m}^{2}\right), Z$ adalah impedansi akustik, konstanta yang tergantung pada transmisibilitas medium dan karakter gelombang suara yang juga sama dengan $c_{0} . \rho$ $\left(\mathrm{N} . \mathrm{s} / \mathrm{m}^{3}\right)$, $\rho$ merupakan densitas udara $\left(\mathrm{kg} / \mathrm{m}^{3}\right)$.

Pada ruang terbuka, $\boldsymbol{v}$ diwakili oleh konstanta kecepatan rambatan suara standar di medium udara $\left(\mathrm{c}_{\mathrm{o}}, \mathrm{m} / \mathrm{s}\right)$. Pada saat memasuki rongga telinga luar, luas area paparan gelombang suara berubah menjadi luas penampang lintang rongga telinga luar. Jika didekati dengan bentuk silinder homogen, maka luasan area paparan pada rongga telinga luar adalah lingkaran. Jadi, perubahan tekanan gelombang suara gending yang menyentuh gendang telinga dapat dituliskan sebagai berikut.

$p=c_{o} A Z=c_{o}^{2} \rho A=\frac{1}{2} \pi r_{e}^{2} c_{o}^{2} \rho$

Untuk $r_{\mathrm{e}}$ adalah jari-jari rongga saluran telinga luar. Dengan menyamakan persamaan 1 dan 3, akan dapat ditemukan persamaan perubahan amplitudo suara gending yang mengenai gendang telinga. Secara umum persamaan tersebut dapat dinyatakan sebagai berikut.

$x(t)= \pm K_{G}\left(\frac{1}{2} \pi r_{e}^{2} c_{o}^{2} \rho p_{o}\right)$

$K_{G}$ adalah konstanta gending yang tergantung pada jenis gending yang digunakan dan didapat dari perhitungan akar persamaan polinomial tiap gending tinjauan. 
GENDING LADRANG PELOG
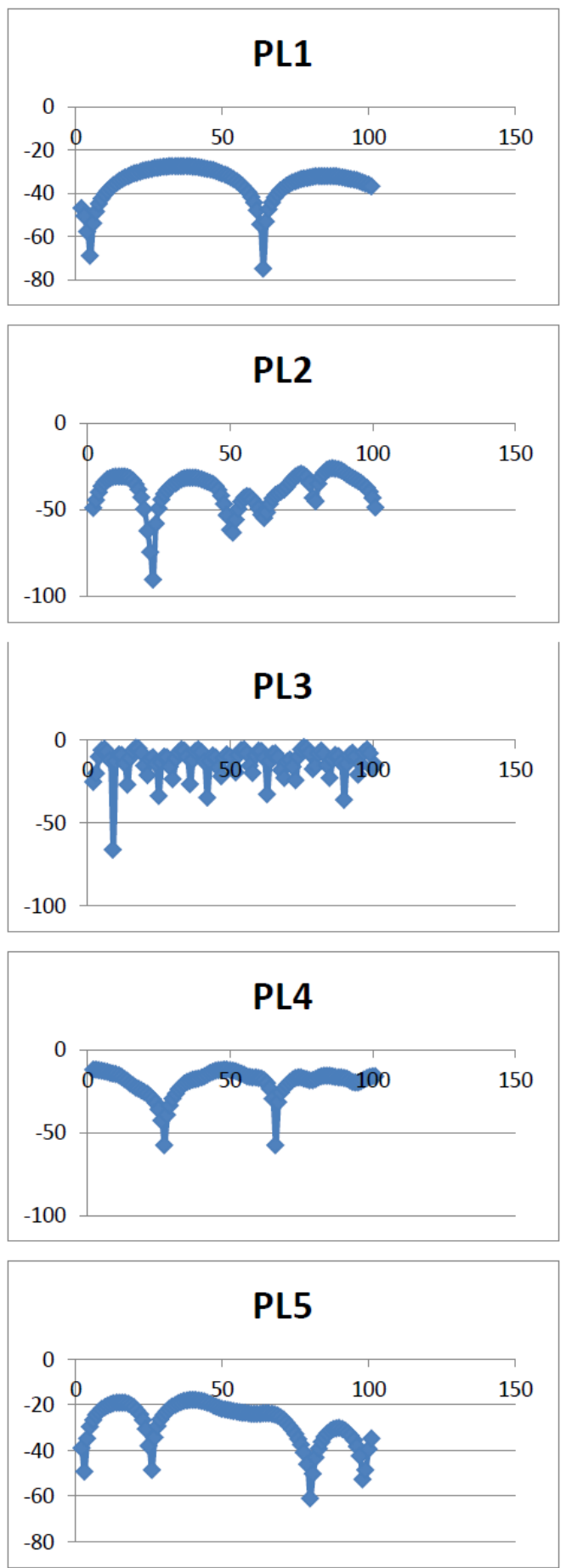
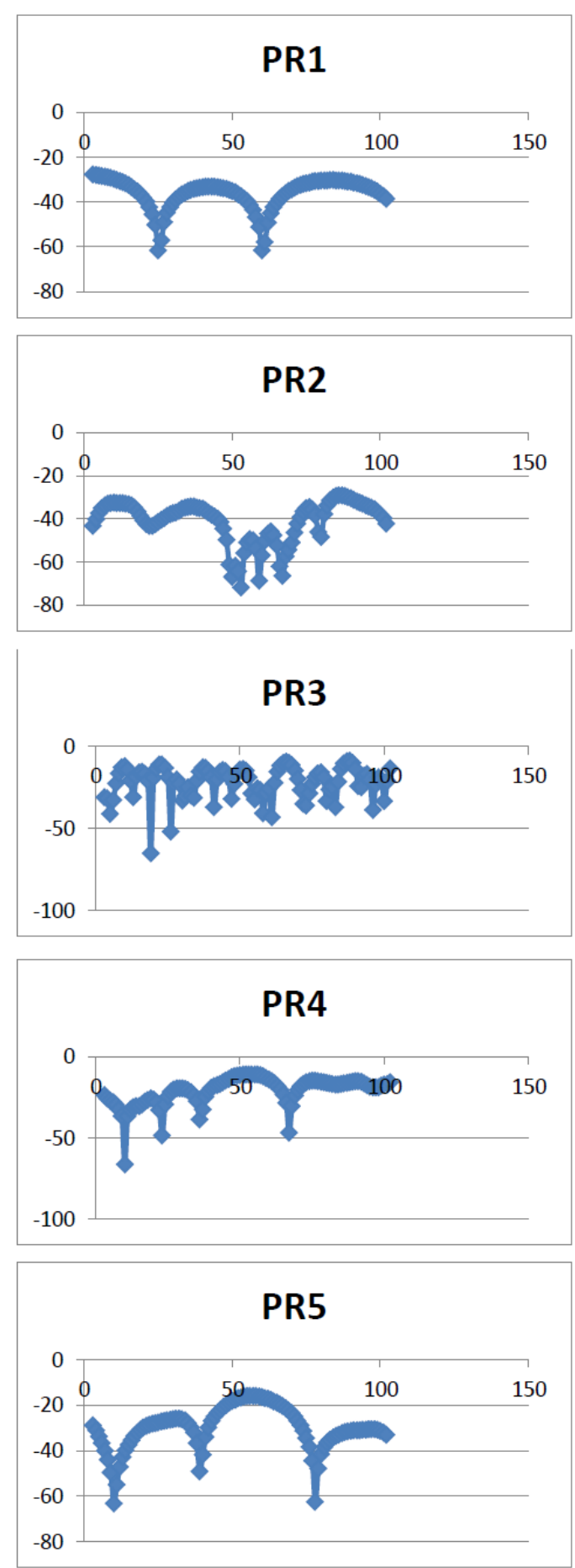

(a) 
GENDING LADRANG SLENDRO
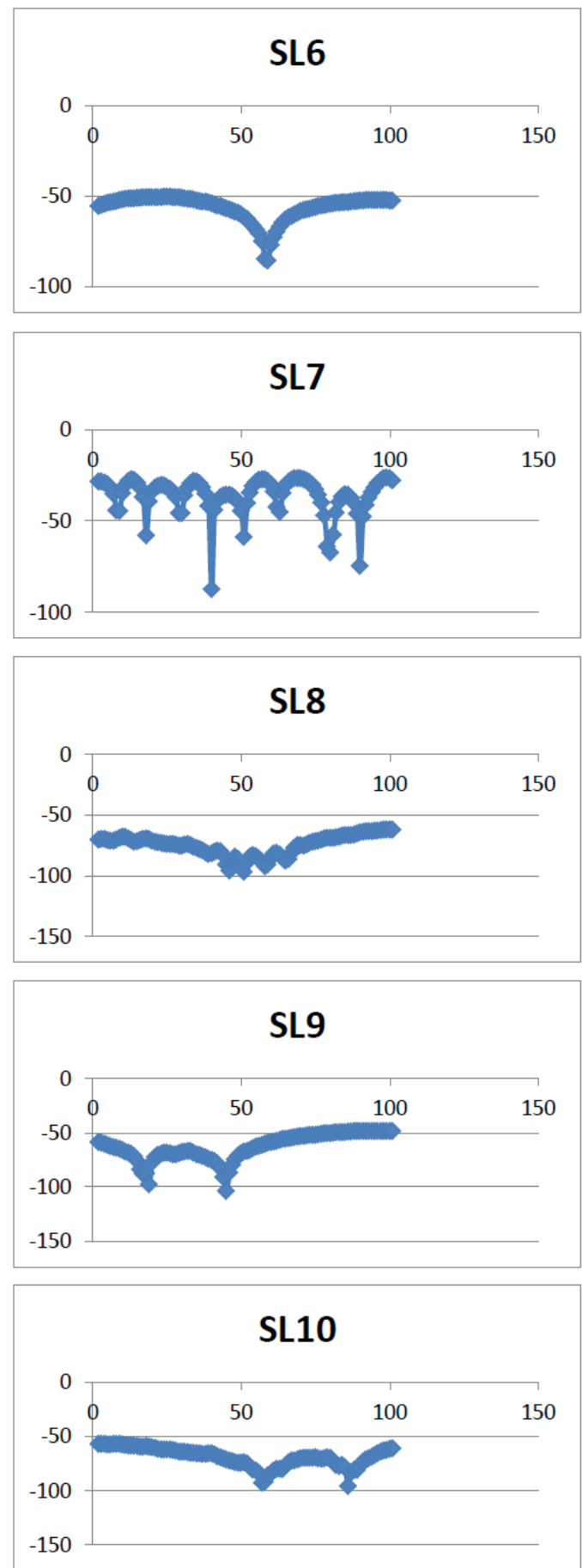

(b)
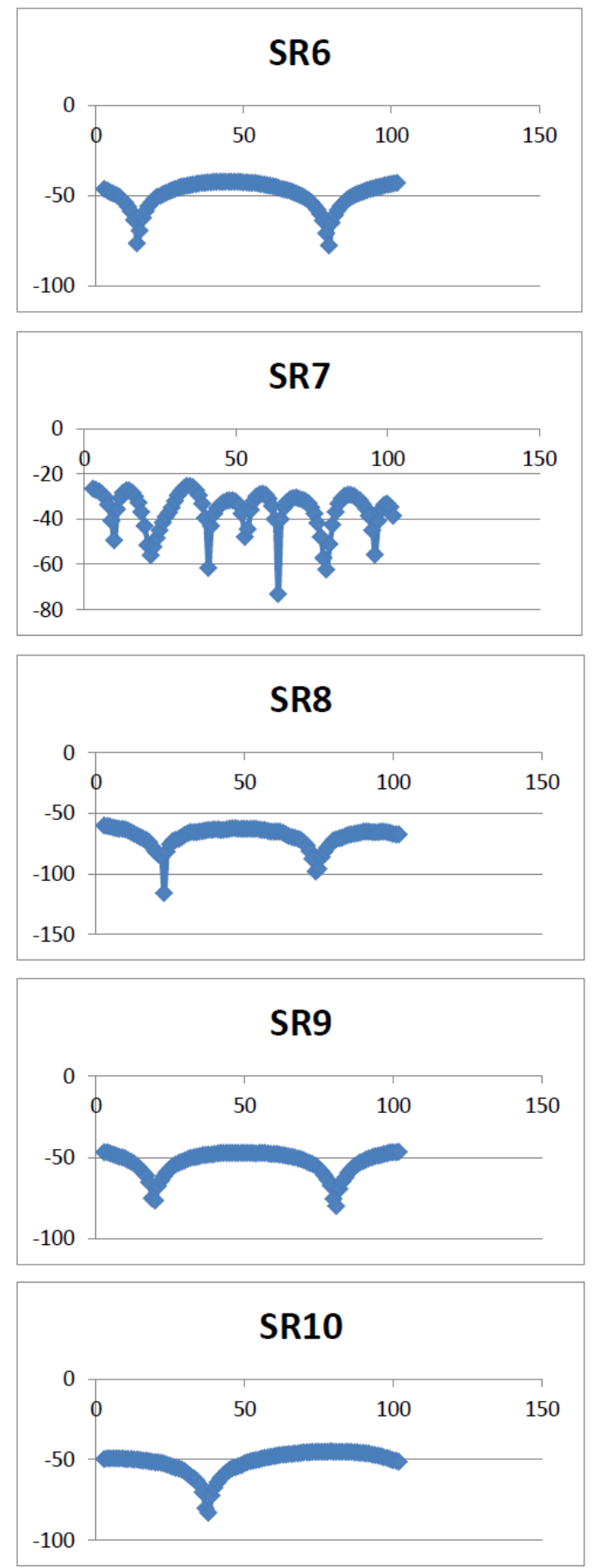

Gambar 3. Pola grafis amplitudo gending dan tembang Jawa; (a) PL-PR, (b) SL-SR 
PEMBANDING
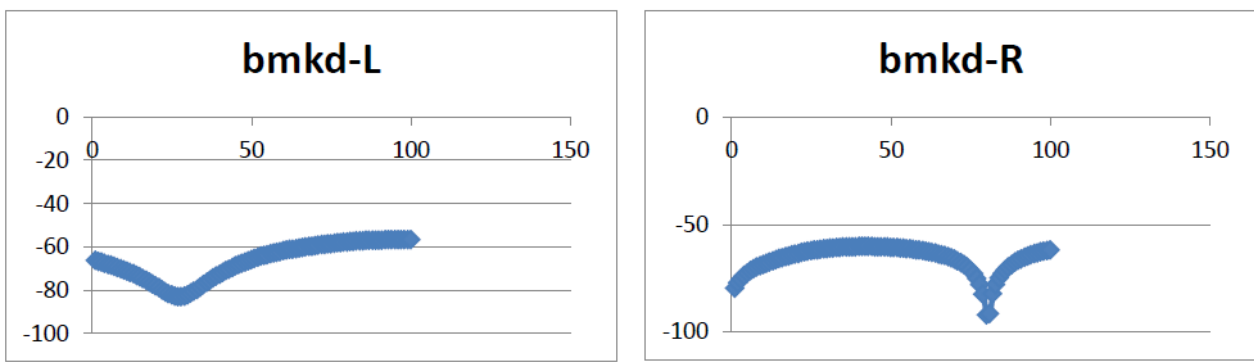

GENDING BIMO KURDO
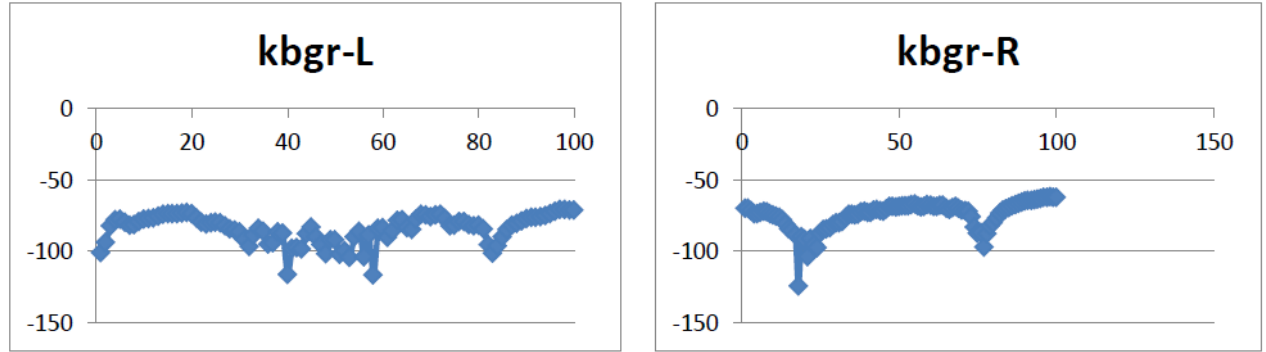

GENDING KEBOGIRO
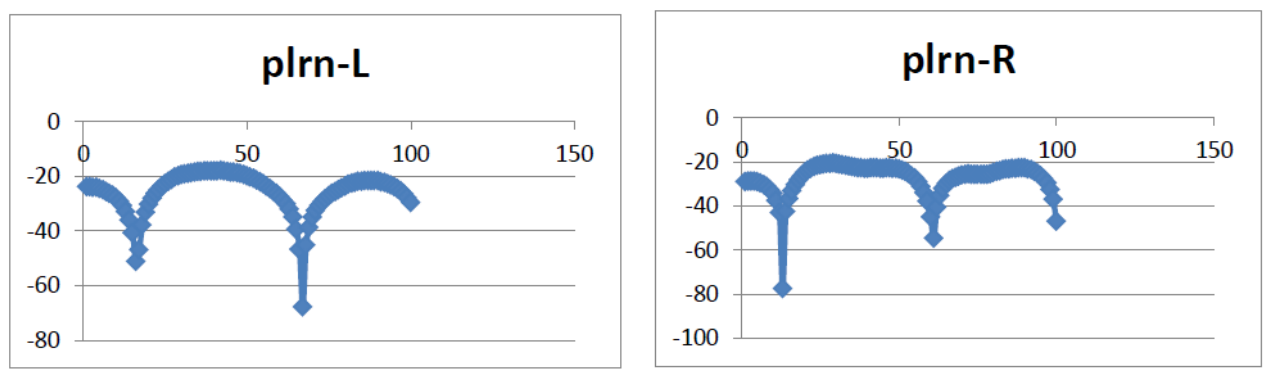

GENDING PALARAN PANGKUR KINANTHI ASMARADANA PEMBANDING LAGU POPULER
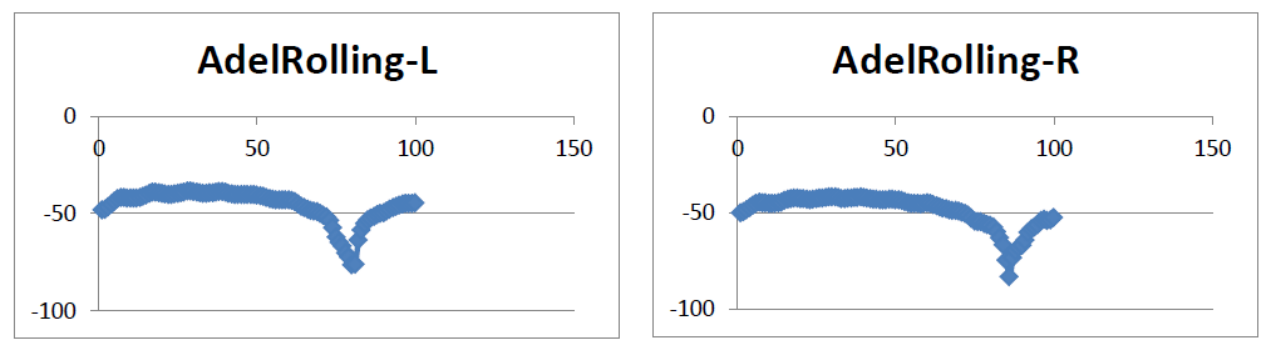

ADEL - ROLLING IN THE DEEP
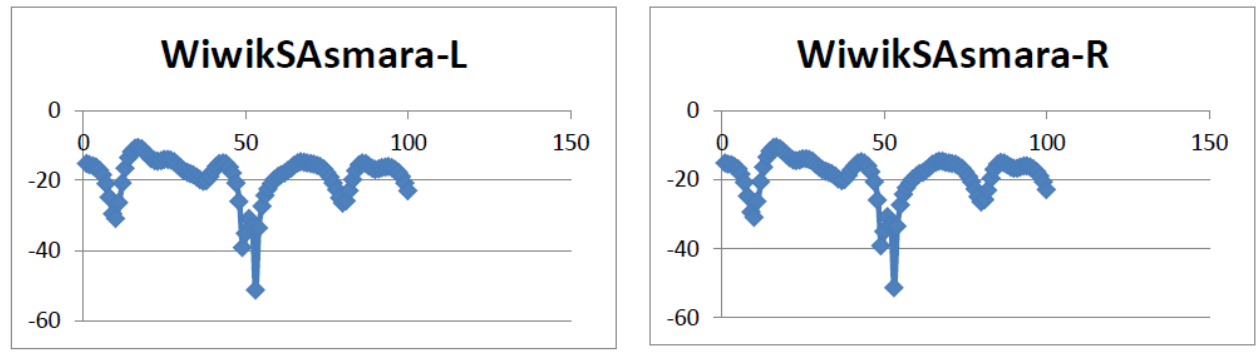

WIWIK S - ASMARA

Gambar 4. Pola grafis amplitudo lagu-lagu pembanding 
Tabel 2. Contoh hasil uji statistik terhadap nilai perulangan pola. Hasil uji untuk Gending Pelog 1 dan 2, pola kanan dan kiri. Hasil selengkapnya untuk semua gending dan tembang tidak ditampilkan

Paired Samples Test

\begin{tabular}{|c|c|c|c|c|c|c|c|c|c|}
\hline & & \multicolumn{5}{|c|}{ Paired Differences } & \multirow[b]{3}{*}{$t$} & \multirow[b]{3}{*}{ df } & \multirow[b]{3}{*}{ Sig. (2-tailed) } \\
\hline & & \multirow[b]{2}{*}{ Mean } & \multirow[b]{2}{*}{ Std. Deviation } & \multirow{2}{*}{$\begin{array}{l}\text { Std. Error } \\
\text { Mean }\end{array}$} & \multicolumn{2}{|c|}{$\begin{array}{l}95 \% \text { Confidence } \\
\text { Interval of the } \\
\text { Difference }\end{array}$} & & & \\
\hline & & & & & Lower & Upper & & & \\
\hline Pair 1 & PL11 - PL12 & 3.15925 & 2.84127 & .46710 & 2.21193 & 4.10658 & 6.764 & 36 & .000 \\
\hline Pair 2 & PR11 - PR12 & -.18744 & 11.80370 & 2.36074 & -5.05977 & 4.68488 & -.079 & 24 & .937 \\
\hline Pair 3 & PR11 - PR13 & -2.02415 & 13.37049 & 2.67410 & -7.54321 & 3.49492 & -.757 & 24 & .456 \\
\hline Pair 4 & PR12 - PR13 & -1.83670 & 1.62847 & .32569 & -2.50890 & -1.16451 & -5.639 & 24 & .000 \\
\hline Pair 5 & PL21 - PL22 & -1.01374 & 8.50768 & 1.90237 & -4.99545 & 2.96798 & -.533 & 19 & .600 \\
\hline Pair 6 & PL21 - PL23 & 1.99263 & 8.04115 & 1.79806 & -1.77074 & 5.75601 & 1.108 & 19 & .282 \\
\hline Pair 7 & PL21 - PL24 & -5.78013 & 5.16628 & 1.15522 & -8.19802 & -3.36223 & -5.004 & 19 & .000 \\
\hline Pair 8 & PL22 - PL23 & 3.00637 & 4.15248 & .92852 & 1.06294 & 4.94979 & 3.238 & 19 & .004 \\
\hline Pair 9 & PL22 - PL24 & -4.76639 & 6.48006 & 1.44899 & -7.79915 & -1.73363 & -3.289 & 19 & .004 \\
\hline Pair 10 & PL23 - PL24 & -7.77276 & 8.23095 & 1.84050 & -11.62496 & -3.92055 & -4.223 & 19 & .000 \\
\hline Pair 11 & PR21 - PR22 & 1.46543 & 4.61556 & 1.03207 & -.69472 & 3.62558 & 1.420 & 19 & .172 \\
\hline Pair 12 & PR21 - PR23 & -3.54504 & 1.87198 & .41859 & -4.42116 & -2.66893 & -8.469 & 19 & .000 \\
\hline Pair 13 & PR22 - PR23 & -5.01047 & 4.71812 & 1.05500 & -7.21862 & -2.80232 & -4.749 & 19 & .000 \\
\hline
\end{tabular}

Tabel 3. Rangkuman model matematis gendang dan tembang Jawa

\begin{tabular}{|c|c|c|}
\hline \multirow{2}{*}{ Code } & \multicolumn{2}{|c|}{ Polinomial regression orde } \\
\hline & Left (L) & Right $(\mathrm{R})$ \\
\hline $\mathrm{P} 1$ & 4 & 2 \\
\hline P2 & 3 & 3 \\
\hline P3 & 2 & 2 \\
\hline P4 & 6 & 4 \\
\hline P5 & 4 & 3 \\
\hline S6 & 3 & 4 \\
\hline S7 & 2 & 2 \\
\hline S8 & 4 & 4 \\
\hline s9 & 4 & 4 \\
\hline S10 & 2 & 3 \\
\hline \multicolumn{3}{|c|}{ Rata-rata orde 3 dengan modus 4} \\
\hline
\end{tabular}



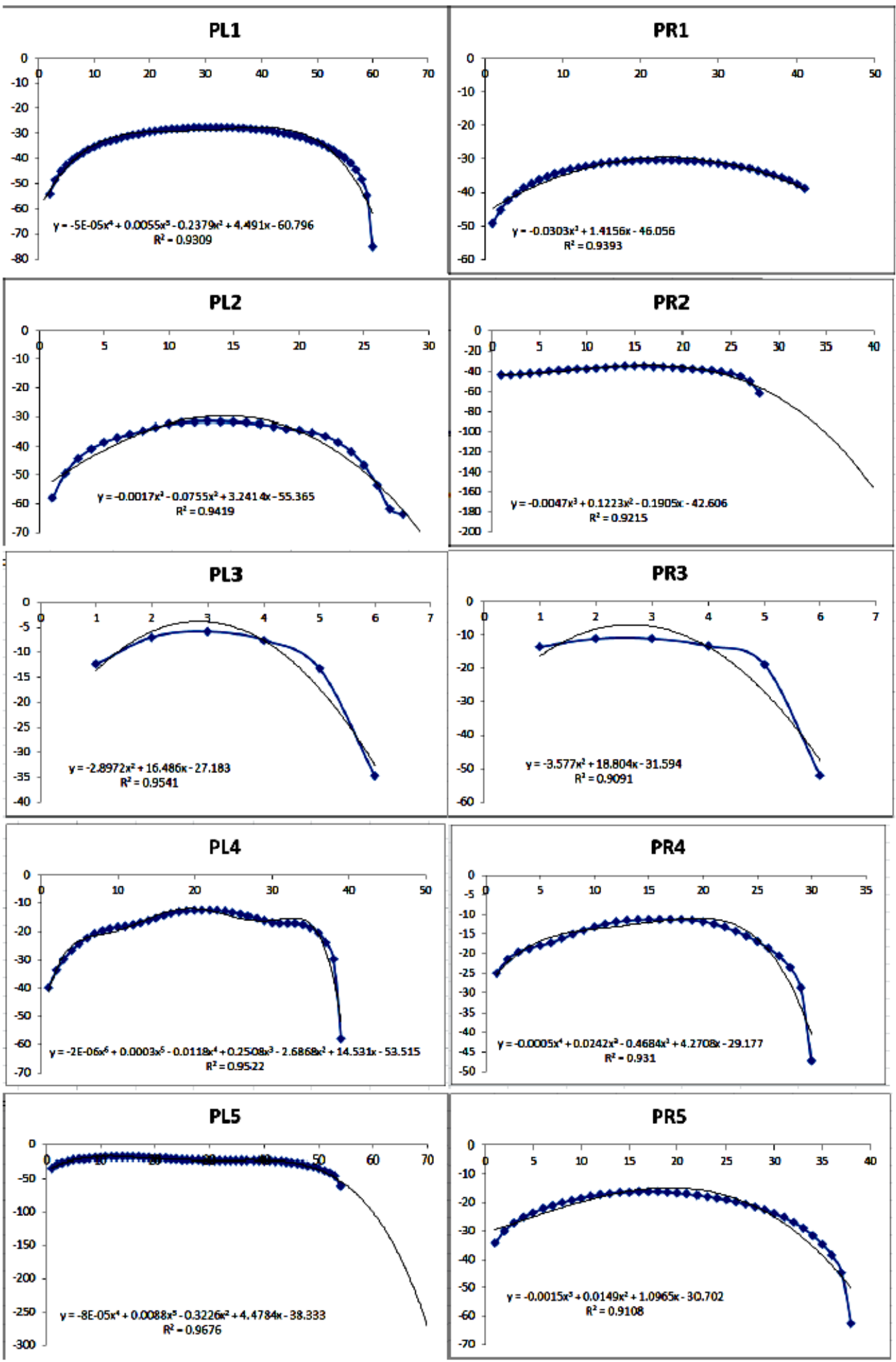

(a)

https://doi.org/10.29303/dtm.v7i1.2 


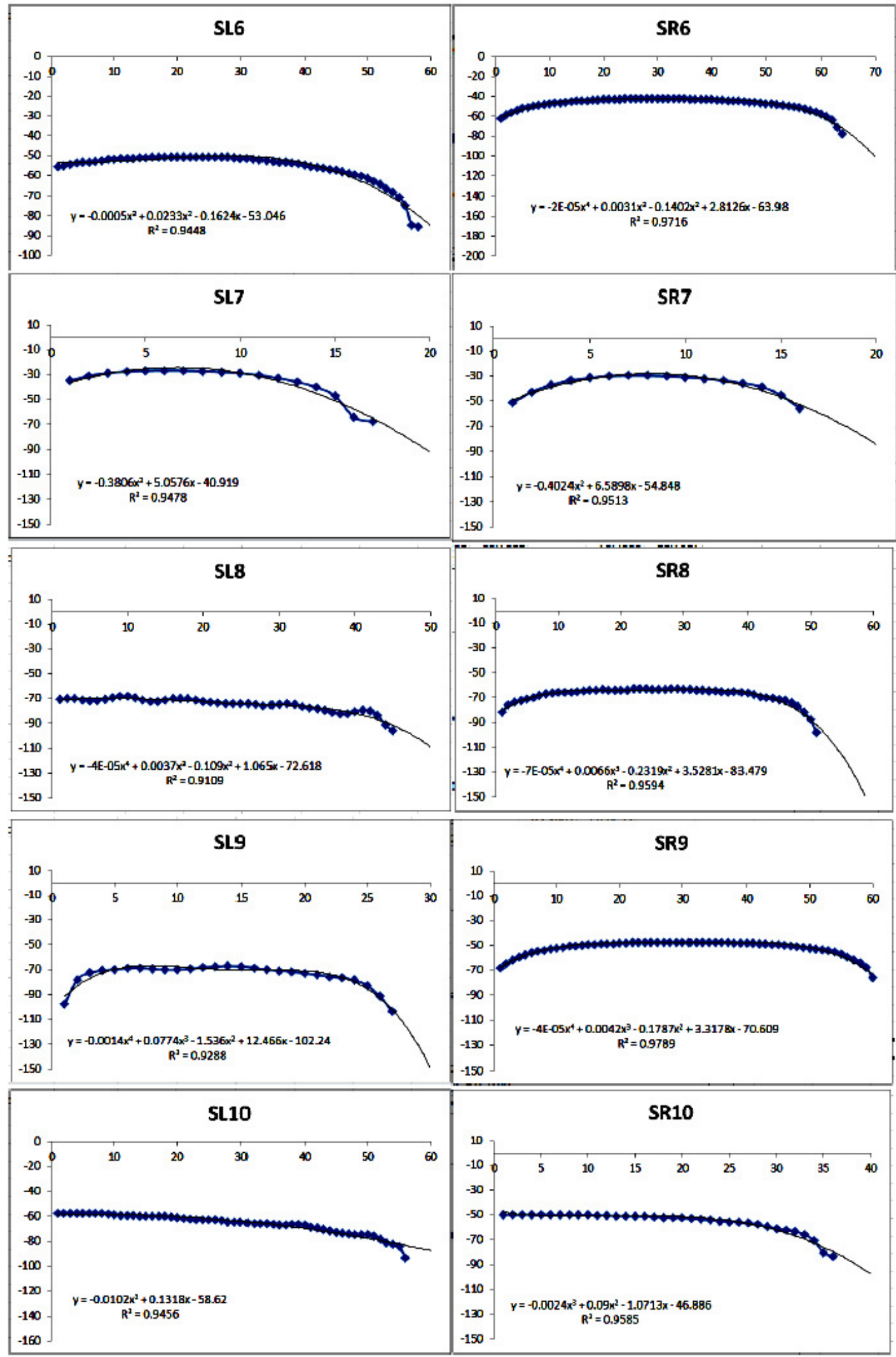

(b)

Gambar 5. Persamaan matematis gending dan tembang acuan, didasarkan dari hasil analisis regresi polinomial dengan faktor kesesuaian $\geq 0.9$; (a) PL-PR, (b) SL-SR

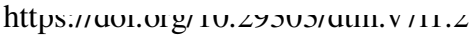



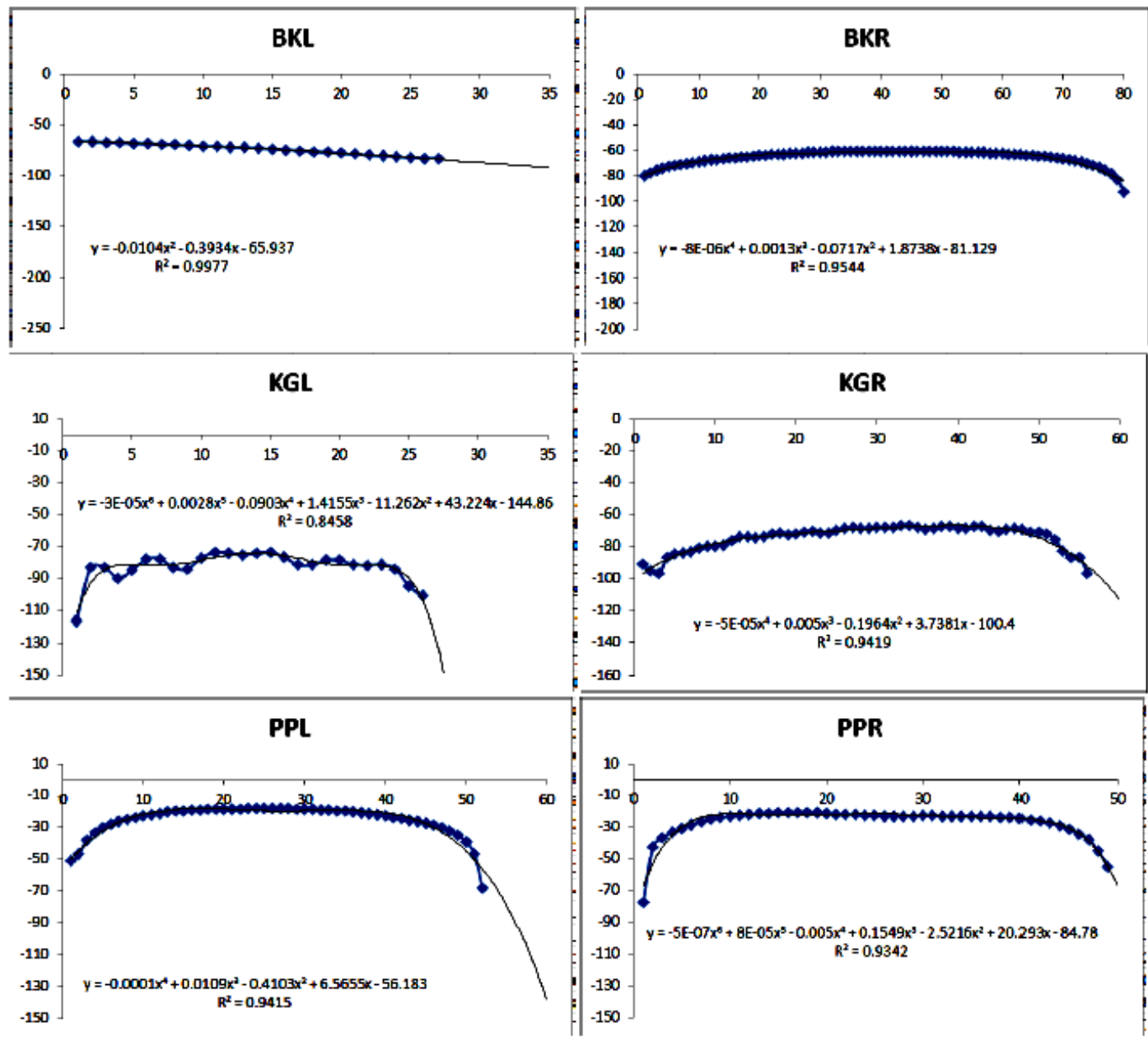

\begin{tabular}{|c|c|c|c|c|}
\hline \multirow{2}{*}{\multicolumn{2}{|c|}{ Title }} & \multirow{2}{*}{ Code } & \multicolumn{2}{|c|}{$\begin{array}{c}\text { Polinomial regression } \\
\text { orde }\end{array}$} \\
\hline & & & Left $(L)$ & Right (R) \\
\hline 1. & Bimo Kurdo & BK & 2 & 4 \\
\hline 2. & Kebogiro & KG & 6 & 4 \\
\hline 3. & $\begin{array}{l}\text { Palaran Pangkur- } \\
\text { Kinanthi-Asmaradana- } \\
\text { Slendro Manyura }\end{array}$ & PP & 4 & 6 \\
\hline * & of orde : 4 in average of & & & \\
\hline
\end{tabular}

Gambar 6. Hasil analisis model matematis untuk gending pembanding 


\section{KESIMPULAN DAN SARAN Kesimpulan}

Penelitian ini menghasilkan temuan persamaan umum untuk transmisi getaran suara gendingdalam bentuk $x(t)= \pm K_{G}\left(\frac{1}{2} \pi r_{e}^{2} c_{o}^{2} \rho p_{o}\right)$.

Dari persamaan tersebut ditemukan potensi angka spesifik yang menggambarkan karakteristik akustik gending yang dinamakan sebagai Konstanta Gending $\left(\mathrm{K}_{\mathrm{G}}\right)$.

\section{Saran}

Masih diperlukan kajian lebih detail untuk dapat menetapkan $\mathrm{K}_{\mathrm{G}}$ sebagai satu konstanta yang berlaku umum untuk gending Jawa. Diduga bahwa konstanta gending tersebut terkait dengan jenisnya (langgam) gending. Ini bisa dijadikan materi penelitian berikutnya.

\section{UCAPAN TERIMA KASIH}

Artikel ini merupakan bagian dari hasil penelitian dalam kerangka hibah Dikti untuk skim Penelitian Hibah Bersaing untuk Tahun Anggaran 2015 dan 2016

\section{DAFTAR PUSTAKA}

Adolphs R., 2002, Recognizing emotion from facial expressions: psychological and neurological mechanisms, Behavioral and Cognitive Neuroscience Reviews, 1, 21-61.

Anderson B.J., Li X, Alcantara A.A., Isaacs K.R., Black J.E., Greenough W.T., 1994, Glial hypertrophy is associated with synaptogenesis following motor-skill learning, but not with angiogenesis following exercise, Glia,11, 73-80.

Arlinger S., Elberling C., Bak C., Kofoed B., Lebech J., Saermark K., 1982, Cortical magnetic fields evoked by frequency glides of a continuous tone, EEG \& Clinical Neurophysiology, 54, 642-653.

Craig A.D., 2002, How do you feel? Interoception: the sense of the physiological condition of the body, Nature Reviews Neuroscience, 3, 655-666.

Critchley H.D., Elliott R., Mathias C.J., Dolan R.J., 2000, Neural activity relating to generation and representation of galvanic skin conductance responses: a functional magnetic resonance imaging study, The Journal of Neuroscience, 20, 3033-3040.

Friedman D.P., Murray E.A., O'Neill J.B., Mishkin M., 1986, Cortical connections of the somatosensory fields of the lateral sulcus of macaques: evidence for a corticolimbic pathway for touch. J Comp Neurol, 252, 323-347.
Gaab N., Schlaug G., 2003, The effect of musicianship on pitch memory in performance matched groups, NeuroReport, 14, 2291-2295.

Gaser C., Schlaug G., 2003, Brain structures differ between musicians and non-musicians, J Neurosci, 23, 9240-9245.

Griffiths T.D., 1999, Human complex sound analysis, Clin Sci, 96, 231-234.

Hudspeth A.J., Konishi M., 2000, Auditory neuroscience: Development, tranduction and integration, Proceedings of the National Academy of Sciences, United States of America, 97, 11690-11691.

lakovides S.A., Iliadou V.T.H., Bizeli V.T.H., 2004, Psychophysiology and psychoacoustics of music: Perception of complex sound in normal subjects and psychiatric patients, Annals of General Hospital Psychiatry, 3, 6.

Janata P., Birk J., Van Horn J., Leman M., Tillmann B., \& Bharucha J., 2002, The cortical topography of tonal structures underlying Western music, Science, 298, 2167-70.

Lütkenhöner B., 2007, Threshold and Beyond: Modeling The Intensity Dependence of Auditory Responses, JARO 9, 102-121.

Okamoto H., Stracke H., Ross B., Kakigi R., Pantev C., 2007, Left hemispheric dominance during auditory processing in a noisy environment, BMC Biology, 5, 52.

Okamoto H., Stracke H., Switserlood P., Roberts L.E., Pantev C., 2009, Frequency-specific modulation of population-level frequency tuning in human auditory cortex, BMC Neuroscience, 10, 1.

Öngür D., An X., Price J.L., 1998, Prefrontal cortical projections to the hypothalamus in macaque monkeys, Journal of Comparative Neurology, 40(1), 480-505.

Öngür D., Price J.L., 2000, The organization of networks within the orbital and medial prefrontal cortex of rats,monkeys, and humans, Cerebral Cortex, 10, 206-219.

Rauscher F.H., Shaw G.L., Ky K.N., 1995, Listening to Mozart enhances spatialtemporal reasoning: towards a neurophysiological basis, Neurosci Lett, 185:44-47.

Safitri A., 2012, Perbandingan manfaat terapi distraksi musik klasik Mozart dan Langgam Jawa terhadap tingkat nyeri dan kecemasan pada ibu Primipara di Puskesmas Mergangsan dan Jetis Yogyakarta, Skripsi, Jurusan IImu Keperawatan Univ. Muhammadiyah Yogyakarta, Indonesia. 
Tortora G.F., 2005, Principles of human anatomy, tenth edition, John Wiley \& Sons, Inc, Hoboken NJ 07030, USA.

Tramo M.J., 2001, Biology and music: Music of the hemispheres, Science, 291(5501), 54-6.

Tsuchiya N., Adolphs R., 2007, Emotion and consciousness, Trends in Cognitive Sciences 11, 158-167.

Wong P.C.M., Perrachione T.K., Margulis E.H., 2009, Effects of Asymmetric Cultural Experiences on the Auditory Pathway Evidence from Music, Ann N Y Acad Sci, 1169: 157-163. 